\title{
Innovation results of IAM planning in urban water services
}

\author{
M.A. Cardoso*, A. Poças *, M.S. Silva*, R. Ribeiro*, M.C. Almeida*, R.S. Brito*, S.T. Coelho**, H. \\ Alegre* \\ * LNEC - National Laboratory for Civil Engineering, Portugal. Avenida do Brasil, 101, 1700-066 Lisbon, Portugal \\ (macardoso@lnec.pt; mssilva@lnec.pt; apocas@lnec.pt; rribeiro@lnec.pt; mcalmeida@lnec.pt; rsbrito@lnec.pt; \\ halegre@lnec.pt) \\ ** Baseform. Rua Borges Carneiro, 34 R/c, 1200-619 Lisbon, Portugal \\ (sergio.coelho@baseform.org)
}

\begin{abstract}
The requirement to provide continuously the urban water services while infrastructures are ageing, impose the need for increasingly sustainable infrastructure asset management (IAM). To achieve and maintain the adequate levels of service, the AWARE-P IAM methodology has been applied in collaborative projects launched by the National Civil Engineering Laboratory (LNEC), in partnership with IST (Technical University of Lisbon), Addition (software company) and several water utilities. The objective of these projects is to support urban water utilities in the development, implementation and maintenance of IAM plans. To guarantee the success of IAM planning, following the AWARE-P IAM methodology, utilities are required to: consider that the infrastructure has system behaviour and lifespan is indefinite and guarantee the full-alignment of IAM planning with organisation objectives. By analysing the strategic and tactical plans of participating utilities, the proposed methodology principles are discussed and supported. The main innovation results from the implementation of IAM planning are also presented and discussed, including the challenges of setting up an IAM process, together with the major benefits and drawbacks that come up when developing IAM plans. The results were demonstrated by the effective implementation of 16 strategic and 13 tactical IAM plans by the participating utilities.
\end{abstract}

Keywords

Infrastructure asset management, urban water services, strategic planning, tactical planning.

\section{INTRODUCTION}

Worldwide, significant investments have been made in urban water infrastructures to provide water services (e.g., water, wastewater or stormwater) and to guarantee their quality. These, are services fundamental for the protection of public health, population well-being, community sustainable development and environmental protection. The requirement to provide continuously the service while infrastructures are ageing, impose the need for increasingly sustainable infrastructure asset management (IAM). Achieving and maintaining adequate levels of service, in a long-term perspective, requires that IAM takes into account that urban water infrastructures have indefinite lifespans, as well as balances performance, risk and cost dimensions (Alegre et al., 2013).

In Portugal, most urban water systems were built during the 80's and 90's. By the end of the $20^{\text {th }}$ century, people living in urbanized areas (cities and rural areas) already had full access to water supply and wastewater services (Alegre and Covas, 2010; Almeida and Cardoso, 2010). Due to this rapid growth, high investments were made, which were also localised in time. As result, there was lower capital availability for the adequate rehabilitation and maintenance levels throughout the infrastructure indefinite functional and operational lifetimes. When systems are not managed properly, the quality of the service provided is compromised, thus resulting in low performance levels and, later on, in impacts over the infrastructure's general sustainability and functionality. There is a growing focus on the best ways to finance and implement improvements in operation, maintenance and rehabilitation of urban water systems (OECD, 2007).

With the objective of supporting urban water utilities in the development, implementation and maintenance of IAM plans, LNEC (National Civil Engineering Laboratory) launched, in partnership 
with the IST (Technical University of Lisbon), Addition (software development company) and a set of water utilities, the Portuguese Initiatives for Infrastructure Asset Management - iGPIs. These are collaborative projects for IAM development following the AWARE-P approach (Alegre et al., 2011). The first edition - iGPI 2012/2013 - involved the participation of 19 utilities and consulting companies (Leitão, et al., 2014). The second edition, iGPI 2015, which is currently ongoing, combines 9 new comer utilities and 9 utilities that had also participated in iGPI 2012/2013, or in other initiative projects (such as PGPI ${ }^{1}$, iPerdas ${ }^{2}$ ) (Coelho et al., 2015). The last utilities mentioned get support to review and enhance their IAM organizational process and plans. The iGPI second edition benefits from an in-depth critical analysis of the first edition AWARE-P methodology application and results, which are the focus of this paper.

Herein, the main innovation results of IAM planning achieved during iGPI 2012/2013 are presented. These include the main challenges that urban water utilities face when setting up an IAM process and the major benefits and drawbacks that come up in IAM plans development through implementation of the recommended methodology. By analysing the strategic and tactical planning level results, the principles of the proposed methodology are discussed and supported.

\section{iGPI - COLLABORATIVE PROJECTS FOR IAM IMPLEMENTATION}

Portuguese Initiatives for Infrastructure Asset Management - iGPIs are collaborative projects for IAM planning in water utilities following the AWARE-P approach. The first edition started in 2012, following up the achievements of the AWARE-P project (http://www.aware-p.org), where the applied IAM methodology for urban water infrastructures was developed (Alegre et al., 2011). All iGPI participating water utilities followed the AWARE-P IAM planning methodology, which is based on continuous improvement following the Plan-Do-Check-Act (PDCA) principles. These include the establishment of an objective driven assessment system for IAM planning, within the defined planning horizon, considering the key requirements of the ISO 55000/55001/55002 standards on asset management (ISO, 2014 a,b,c). The assessment system is supported by objectives, assessment criteria, metrics, reference values and targets, defined at the strategic, tactical and operational levels of planning (Figure 1). In addition, they need to be fully aligned between themselves in order to enable progress monitoring of the IAM plan implementation and to ensure objectives compliance at all planning levels.

Supported by technical guides (Alegre and Covas, 2010; Almeida and Cardoso, 2010), training courses and software (AWARE-P, aware-p.org), the main outcomes of the iGPI initiative project are, along with the utilities capacity-building process, the IAM strategic and tactical plans produced by the participating utilities (Leitão et al., 2014). Through the development of the IAM plans, and by the time of their finalisation, each utility's project team receive continuous feedback and participate in regular follow-up discussions. This helps to attest the progress of the work and compliance with the project's achievements, as well as the processes of knowledge transfer and capacitation. By the end of the initiatives, individual reporting of the results achieved by each of the utilities, with suggestions, recommendations and opportunities for plans improvement, is documented and delivered to each utility team leader and administration board.

\section{THE AWARE-P IAM METHODOLOGY}

A successful IAM planning requires meeting the methodology’s main principles, which include: (i)

\footnotetext{
${ }^{1}$ PGPI was a twin-project of iGPI 2012/2013 launched by AGS, a private holding of water utilities that has been a LNEC's partner in many collaborative projects. The PGPI adopted LNEC's model for the initiatives to build capacity and promote innovation within their group. PGPI ran simultaneously with iGPI 2012/2013.

2 iPerdas, the National Water Loss Initiative, is a collaborative project launched by LNEC. iPerdas uses the initiatives' model, with the scope in water and energy losses management.
} 
considering that infrastructures behave as a system, i.e., individual water pipe or sewer is not a functional unit, does not provide a service by itself and does not have a value (in terms of service) by itself; (ii) planning for a long-term horizon, taking into account that the infrastructure has indefinite life, goes beyond generations, and thus all phases of the assets lifecycle coexist in an mature infrastructure; (iii) addressing performance, risk and cost. Additionally, is fundamental the full-alignment of the IAM developed plans with the organisation objectives, considering the involvement of the different decisional levels, from front-line staff to top managers At each of the three planning levels (Figure 1), strategic, tactical and operational, it is required to define the plans' scale (level of detail), scope (water supply, wastewater or stormwater services), type of action (strategies, tactics or operations) and horizon (short-, medium- and long-term).
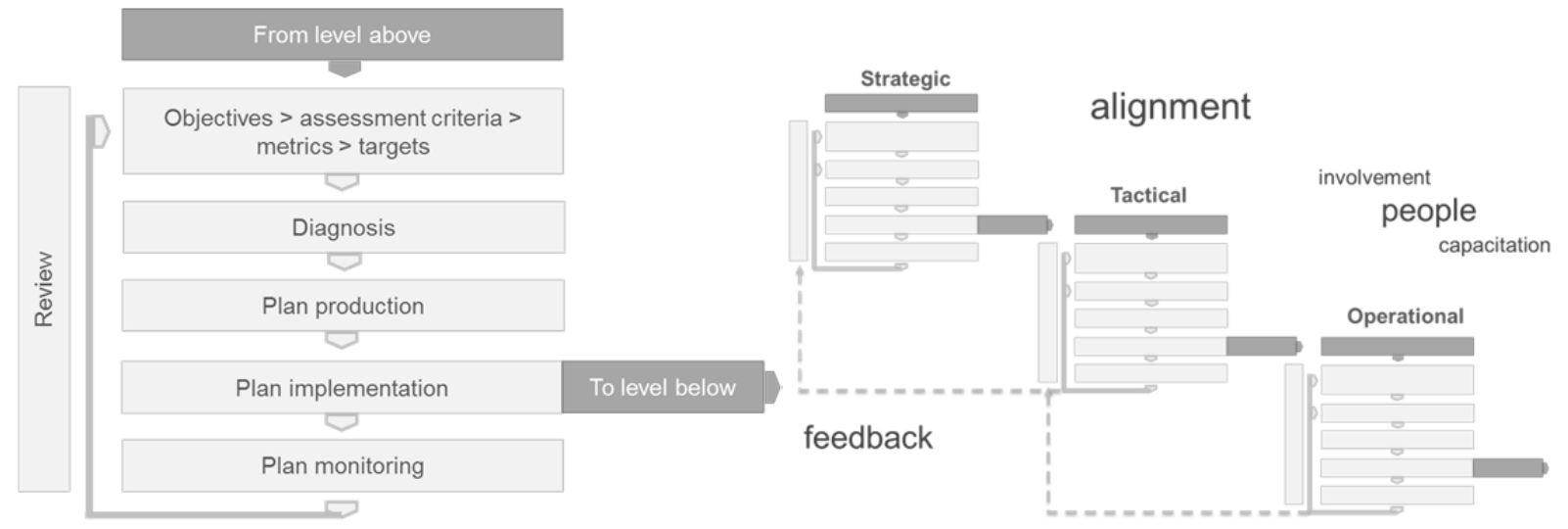

Figure 1. AWARE-P IAM methodology: the planning process at each planning level and its alignment.

The strategic level overlooks at a long-term planning horizon (at least 15 to 20 years) and requires the involvement of the entire organisation. The IAM strategic plan includes: 1) identification of utility's vision and mission, 2) definition of strategic objectives and the correspondent assessment systems - criteria, metrics and reference values, 3) diagnosis, with assessment results of the metrics for the current situation combined with a context (internal and external) evaluation, and 4) identification of strategies to be implemented (Alegre et al., 2011).

The tactical level of planning overlooks at a medium-term planning horizon (up to 3 to 5 years). Like in strategic planning, the IAM tactical plan includes the definition of the tactical objectives and the correspondent assessment systems - criteria, metrics and reference values, as well as the diagnosis, with results from the current situation characterisation. The tactical level of planning also includes a systematic definition of activities, priorities, stages of implementation and schedules, together with the division of the water or wastewater system in functional areas of analysis, i.e., system sectors, if this facilitates the decision-making process. Following the methodology, and by comparing the assessment results obtained in each of the sectors, it is possible to assess the priority areas for intervention that require a more detailed analysis. By studying possible intervention alternatives, combining risk, cost and performance dimensions, the selection of the best alternative, for the study areas, is assessed. Based on the diagnosis, the decision of the best alternative solution will provide a set of tactics, infrastructural and non-infrastructural, to be implemented at the operational planning level. This planning level refers to a short-term horizon, typically 1 year, and it is set to implement the tactics which were previously defined in the tactical plan. This plan should identify and program all the actions to be implemented within the operational planning horizon.

In sum, the strategic objectives should determine where the utility would like to be at the end of the defined long-term planning horizon and the tactical objectives should define the path they need to follow in order to achieve those strategic objectives. With respect to the operational plan, the 
operational objectives should support definition of the actions that need to be taken in order to implement all the defined tactics, thus contributing for compliance with all the objectives.

\section{RESULTS AND DISCUSSION Utilities characterisation}

The 16 full participating utilities in the iGPI 2012/2013 have implemented the AWARE-P methodology in the development of respective IAM plans. These utilities were representative of the overall Portuguese panorama being of different sizes, with population served varying between 3,000 to 390,000 inhabitants, households from 1,342 to 166,469 for water supply (WS) services and from 1,500 to 158,276 for wastewater (WW) services and total pipe length from 51 to 3,831 km for WS systems and from 50 to 1,978 for WW systems. With respect to stormwater (SW) services the information was incomplete. In addition, utilities had different typology (rural, urban), scope (WS, WW, SW), and institutional governance framework (e.g., municipal, inter-municipal, concession).

\section{Strategic planning level}

In total, 16 strategic IAM plans were developed, including WS, WW and SW systems. For the utilities providing more than one service (WS and WW, or WS, WW and SW) the priority was to complete the WS services plans. Utilities were encouraged to internally reflect on the objectives and criteria to establish. Accordingly, multiple internal and iGPI group discussions took place during the project. Regardless, there were common strategic objectives, being the most chosen: (1) Satisfaction of user's needs and expectations; (2) Organisation's sustainability and (3) Environmental sustainability. These objectives correspond to those requested by the Quality of Service Provided assessment system of the Portuguese Water and Waste Services Regulator (ERSAR). All utilities have to comply and report to this system, on a yearly basis. ERSAR establishes reference values for "unsatisfactory", "satisfactory" or "good" assessment metrics results (Alegre et al., 2010).

In the diagnosis for the "current situation" (i.e., data referred to 2011) the most unsatisfactory results correspond to the strategic objective - "organisation's sustainability". This was particularly unsatisfactory for WW systems, in which two out of seven participating utilities showed $100 \%$ of unsatisfactory results. In addition, the main problems identified by the participating utilities included the high levels of water loss (for WS) and of standardised energy consumption (for WW), and, for both WS and WW, the inadequacy number of human resources and low pipe rehabilitation rates (Figure 2). With respect to the SW systems, results were mostly unsatisfactory, being the low pipe rehabilitation rates the most commonly identified problem (Figure 2).

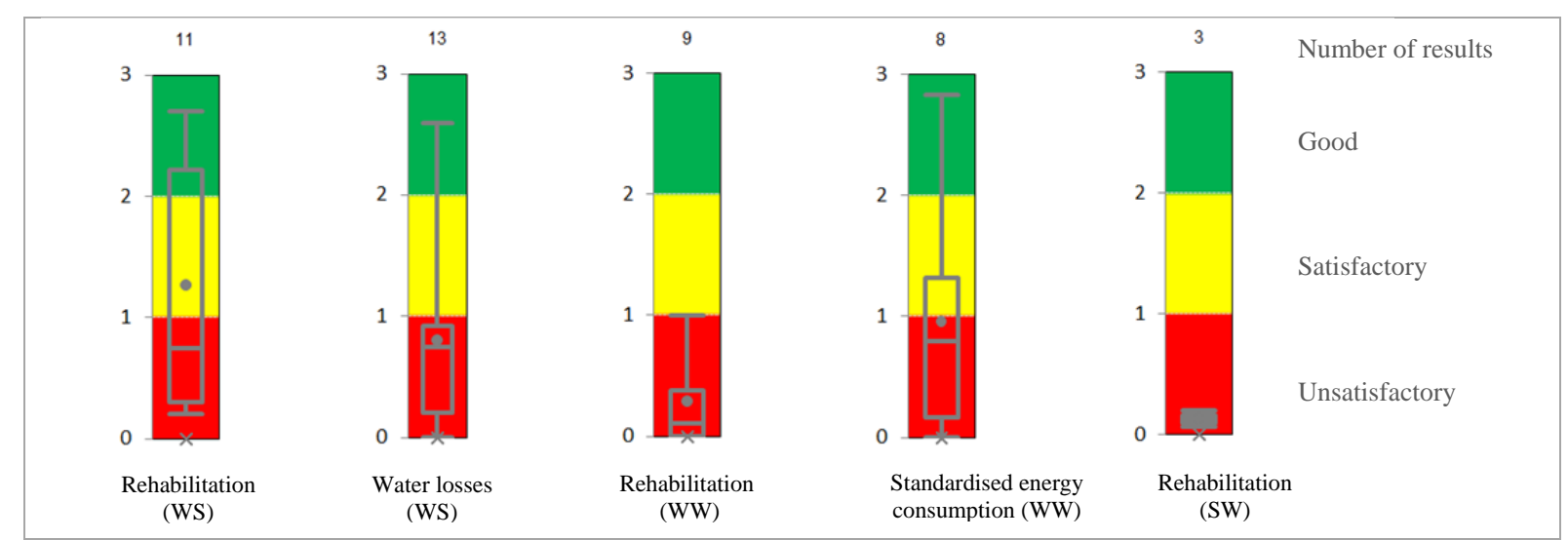

Figure 2. Box plots for the rehabilitation (WS, WW and SW), water losses (WS) and standardised energy consumption (WW) metrics. Dot indicates the "average", the box upper limit the "maximum" and the box lower limit the "minimum” values. 
For the current situation diagnosis, after assessing the metrics, the utilities performed a SWOT (strengths, weaknesses, opportunities and threats) analysis. Therein, the most common "weaknesses" identified were: ageing of the infrastructures, lack of communication within the different information systems and within the organisation, and insufficient/deficient information. The most identified "strengths" were related to: hierarchic structure, good technical and operational competences, available technology and motivated human resources.

Based on the complete diagnosis (assessment system and SWOT analysis), utilities established the strategies to be further implemented (Figure 3) at the tactical level of planning. These strategies were divided in two groups: one addresses infrastructural problems and the other non-infrastructural problems. For each group, tags were defined concerning their most related topic, e.g., "rehabilitation", "human resources", etc. While the infrastructural strategies were mainly related with efficiency and rehabilitation, the non-infrastructural strategies were mainly related with improvement in organisational procedures and enhancement of information management.
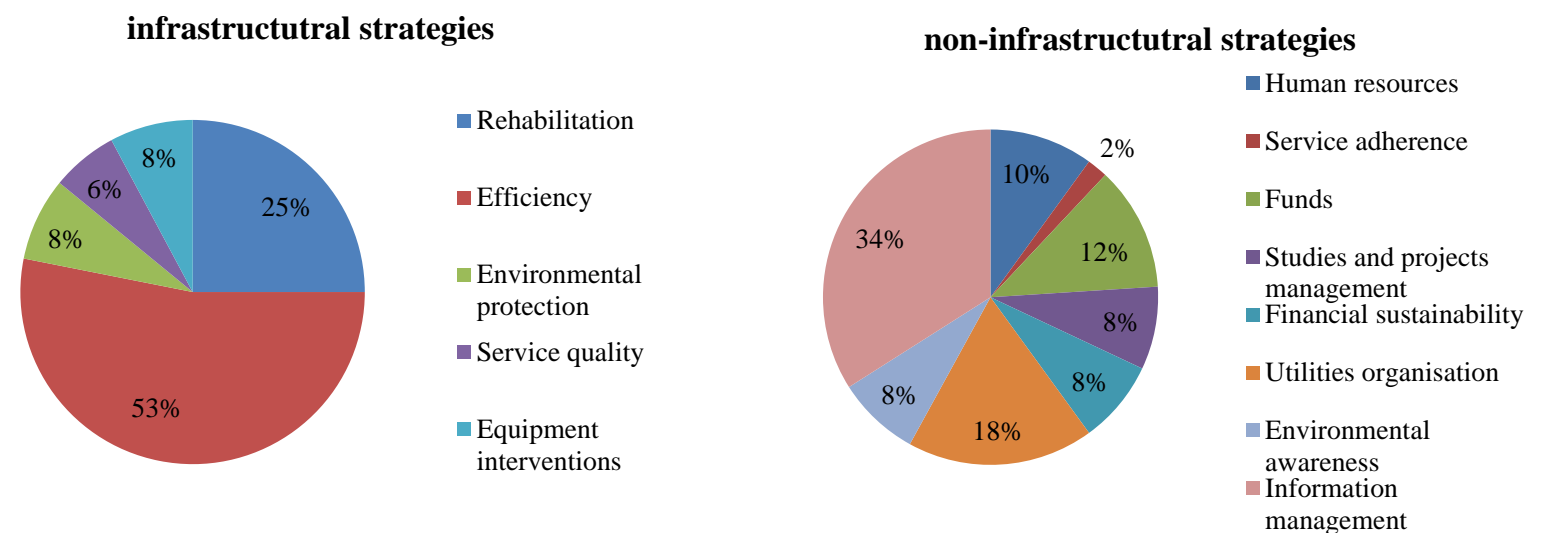

Figure 3. Main identified strategies’ related tags/topics, for infrastructural and non-infrastructural actions.

\section{Tactical planning level}

Based on the strategies developed at the strategic level of planning, 13 tactical plans were developed and completed for the water supply systems, 4 tactical plans for the wastewater systems and 1 tactical plan for the stormwater services. Alike in strategic planning, the selection of metrics for the tactical assessment system was mostly based on ERSAR and IWA systems (Matos et al. 2003; Alegre et al., 2006).), even if some utilities have also defined their own metrics, to control specific issues.

Most of the selected tactical metrics (Figure 4) were aligned with the strategy topics (Figure 3). This shows that the alignment between the two planning levels, which is a key step of the AWARE$\mathrm{P}$ methodology, was guaranteed. In the diagnosis, concerning the WS systems, water efficiency was highlighted as one of the utilities' main concerns, as shown by the non-revenue water and water loss metrics. Likewise, the infrastructure's sustainability was addressed by the mains failure and rehabilitation metrics. For the WW systems, the main concerns were related with effective service, energy consumption and infrastructural sustainability, as shown by the sewer collapses and flooding metrics, and the Infrastructure Value Index (Alegre et al., 2014). This metric was widely chosen since it represents the devaluation degree of an infrastructure, which is particularly important in the mid and long-term planning. For the SW systems, the defined metrics were more dispersed while varying from infrastructural sustainability (IVI, collapses), financial (total cost coverage ratio), social (flooding), to organisation sustainability metrics (human resources).

With the global diagnosis for all systems (i.e., WS, WW and SW), utilities proceeded dividing them into functional assessment areas - system sectors. These correspond to district metering areas, 
basins or subsystems, depending on how the utilities consider being more useful to assess their system at a more detailed level. The number of defined system sectors relates not only to the size of the area under responsibility of the utilities, but also to the level of detail of data and information. For the WS systems, the number of sectors varied from 1 to 63 and, for the WW systems, from 1 to 29. The number of households per sector varies by typology of served areas, with the "mainly rural" having fewer households per sector than the "mainly urban" ones (ca. 1,600 households per area in mainly rural areas, for both WW and WS, and ca. 6,000 and 10,000 households per area, in the mainly urbanized areas, for WW and WS respectively). With respect to conduit/pipe length per sector, no differences were observed between different typologies.

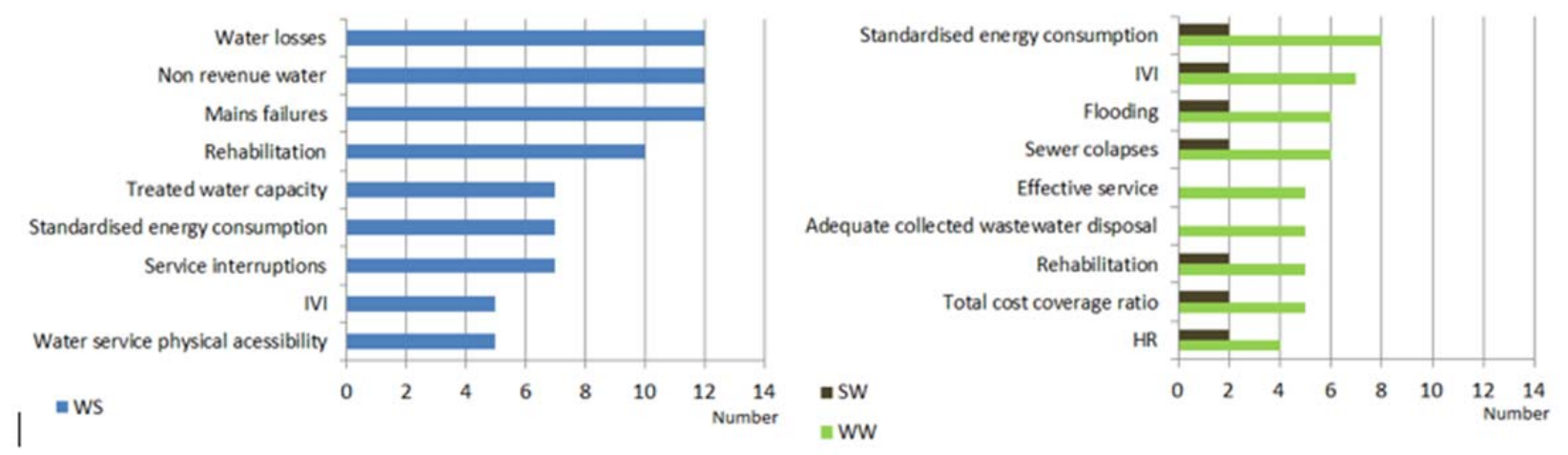

Figure 4. Main metrics chosen by the water utilities in the tactical plans.

Based on the diagnosis of the area of analysis, utilities defined intervention alternatives to solve the problems identified, evaluated the alternatives based on the tactical assessment system, selected the alternative to be implemented and, based on this, established the tactics that needed to be further implemented (Figure 3) at the operational level of planning. Alike in the tactical metrics, the tagged tactics' topics were close to the observed for the strategies, which reconfirms an effective alignment between the two decisional levels of planning (Figures 3 and 4). Likewise, efficiency remained as one of the utilities main concerns, together with infrastructure sustainability (rehabilitation). As for the non-infrastructural tactics, information management remained a top priority.

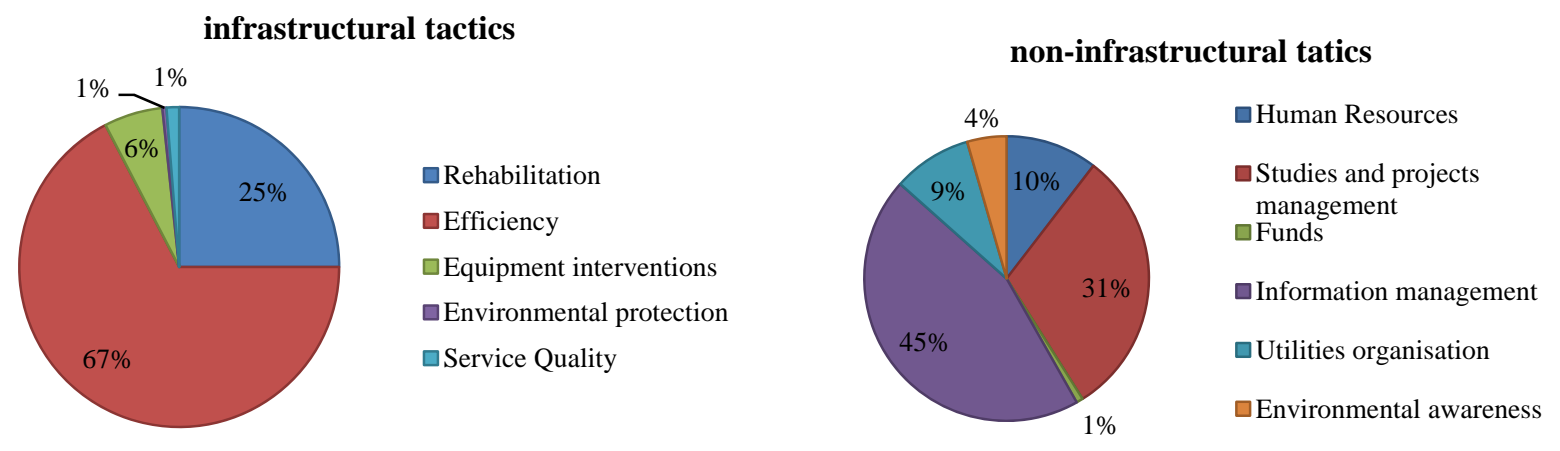

Figure 4. Main identified tactics’ related tags/topics, for infrastructural and non-infrastructural actions.

\section{Final project achievements}

Generally, there were diverse levels of achievement in the different services (WS, WW and SW). It was observed more completed plans for WS than those for WW and SW services. By the end of the project, the tactical IAM plans presented more opportunities for improvements and completion when compared with the strategic plans. In general, for both WS and WW services, strategic IAM plans achieved the iGPI project goals and methodology requirements. The majority of the utilities reached the main goals established for the development of their IAM plans. Follow-up revisions and updates of the plans were further addressed by the utilities themselves, or are currently being 
addressed in the scope of the second edition of the project - iGPI 2015 initiative, with the support of LNEC and the consortium (www.iGPI.aware-p.org). Also based on continuous improvement and following the PDCA principles, this second edition continues providing upgraded tools for supporting the IAM organizational process and the plans completion, monitoring and revision.

\section{Discussion}

iGPI participating utilities were diverse, presenting different contexts and dimension, as emphasized by the numbers of system sectors, which ranged from 1 to 63 for WS and from 1 to 29 for WW services, as well as the higher number of households per sector (4 to 6 times) in urbanized regions than in mainly rural ones. With respect to the level of plan implementation, while most strategic IAM plans were successfully implemented, some of the tactical IAM plans still needed to be reviewed and expanded to other system sectors. This may be explained by the project's schedule, the time needed by the utilities to develop the strategic plans, thus resulting in less time remaining for the development of the tactical plans, or because the tactical planning level usually is more time consuming for gathering the information at system sector level. Also, due to the alignment imposed by the proposed methodology, when developing the tactical plans, the strategic plans experienced adaptations which may have delayed the tactical plan completion. On top of that, as one of the project commitment is to involve the whole organisation, and since the teams are usually composed by middle managers other than top managers, the development of the strategic plan can be longer than initially expected. Relatively to the different services, the most complete plans corresponded to the WS services, either because there was more available and reliable information or due to the priority addressed to the WW and SW plans development. Nevertheless, the best IAM processes and plans do not necessarily corresponded to better resourced utilities.

Despite of the variety of contexts within the participating utilities, their strategic objectives were similar, as well as the type of identified problems. This was shown by the weaknesses identified in the SWOT analysis, together with the types of actions defined by the strategies and tactics.

Being a learn-by-doing experience, this type of collaborative project format has been tested and successfully applied over the years (since 2000). For the participating utilities, the projects have provided competences for applying new models and procedures while increasing awareness for the importance of analysing the problems in an inclusive manner, i.e., involving the decisional levels of the organisation. For the water sector in general, this kind of projects helps to raise awareness to the importance of the issues under analysis and allows new practitioners to test and implement the proposed methodology. Adding to the full-capacitation process by the water utility participants and the dissemination of results within the academic community, the water sector and society have also benefited with GPI initiatives. Guidelines and sample templates for the elaboration of IAM strategic and tactical plans, training materials (presentation slides, recorded webinars, written materials), software tools, industry events to discuss the case studies and products, were made available to the public domain, as well as postgraduate (MSc and $\mathrm{PhD}$ ) dissertations. Also, to further emphasize the impacts and contributions of the AWARE-P project and products to structure IAM in the water sector at an international level, the project was awarded with the 2014 Mulheim Water Award and the 2014 IWA Project Innovation Award (Europe \& West Asia region), in the Planning category.

\section{CONCLUSIONS}

The main innovation results from implementation of IAM planning in urban water utilities are presented and discussed, the focusing on the challenges of setting up an IAM process, results achieved, major benefits and drawbacks. The implementation of IAM planning was performed within the iGPI 2012/2013 initiative collaborative project. Results were demonstrated by the effective implementation of 16 strategic and 13 tactical IAM plans by the participating utilities. 
In the plan development, utilities recognised the importance for decisions of considering the infrastructures system behaviour as well as the long-term horizon. This supports the key principles of the AWARE-P IAM methodology while reinforcing its' applicability to the reality of urban water infrastructures. The main drawbacks are related to lack of communication within the different information systems and within the organisation, as well as insufficient information requiring considerable resources and resulting in a significant effort, if analysed in the short-term. However, in agreement with a long-term quality of the service provision, and in line with the organisation strategic objectives, the application of the AWARE-P methodology through a capacitation processes facilitated and enabled the success of IAM planning.

In spite of the different available technical and technological resources amongst the participating utilities, there was no impact in the development of the IAM plans. In fact, the most important success factors were the commitment of both the project team and top managers. This shows that the methodology may be successfully implemented by utilities with different realities, such as in size or serving areas as well as the IAM maturity stage at the time when the project started. From the research point of view, the variety of contexts and backgrounds was important for the methodology's representativeness and validation. From the utilities' point of view, the variety of contexts and backgrounds was used for active networking with peers and benchmarking, at the same time that it allowed better results throughout the capacitation process. In the second edition, iGPI 2015 is benefiting from an in-depth critical analysis of the first edition results allowing the development of monitoring and revision procedures, assessing the plan implementation effects as well as improving and facilitating the IAM process and plans development.

\section{Acknowledgements}

The authors acknowledge the outstanding efforts and contributions from all the utilities, organizations and individuals that took part in iGPI2012/2013.

\section{References}

Alegre, H., Baptista, J. M., Cabrera Jr, E., Cubillo, F., Duarte, P., Hirner, W., Merkel, W. \& Parena, R. (2006). Performance Indicators for Water Supply Services - Second Edition. IWA Publishing, London, UK.

Alegre, H. e Covas, D., (2010). Gestão Patrimonial de Infra-estruturas de Abastecimento de Água. Uma Abordagem Centrada na Reabilitação. Guia Técnico nº. 16, Série Guias Técnicos, ERSAR/LNEC/IST, Lisboa, (ISBN: 978-989-8360-04-5).

Alegre, H., Coelho, S.T., Covas, D., Almeida, M.C., Cardoso, M.A. (2013). A utility-tailored methodology for integrated asset management of urban water infrastructure. Water Science \& Technology: Water Supply Vol 13 No 6 pp 1444-1451 (C) IWA Publishing 2013 doi:10.2166/ws.2013.108.

Alegre, H., Covas, D., Coelho, S.T., Almeida, M.C., Cardoso, M.A.(2011) Integrated approach for infrastructure asset management of urban water systems. IWA 4th LESAM, 27-30 Sep, Mülheim An Der Ruhr, Germany.

Alegre, H., Vitorino, D., and Coelho, S.T., 2014. Infrastructure value index: A powerful modelling tool for combined longterm planning of linear and vertical assets. Procedia Engineering, 89, 1428-1436.

Almeida, M. C. e Cardoso, M. A., (2010). Gestão Patrimonial de Infra-estruturas de Águas Residuais e Pluviais. Uma Abordagem Centrada na Reabilitação. Guia Técnico nº. 17, Série Guias Técnicos, ERSAR/LNEC, Lisboa, (ISBN: 978989-8360-05-2).

Coelho, S., Alegre, H., Leitão, J.P, Cardoso, M.A., Silva, M.S., Ramalho, P., Ribeiro, R. and Almeidam M.C. (2015). iGPI and PGPI: national-scale cooperative R\&D rollout of IAM planning methods and tools. Water Asset Management International 11.1 (2015) 07-10.

ISO (2014a). ISO/CD 55000: 2014 Asset management — Overview, principles and terminology.

ISO (2014b). ISO/CD 55001:2014 Asset management — Management systems — Requirements.

ISO (2014c). ISO/CD 55002:2014 Asset management — Management systems — Guidelines for the application of ISO 55001.

Leitão, J.P., Coelho, S.T., Alegre, H., Cardoso, M.A., Santos Silva, M., Ramalho, P., Ribeiro, R., Covas, D., Poças, A.,

Matos, R., Cardoso, A., Duarte, P., Molinari, A. \& Shulz, A.(2003). Performance Indicators for Wastewater Services. IWA Publishing, London, UK.

Vitorino, D., Almeida, M.C., Carriço, N. (2014). Moving urban water infrastructure asset management from science into practice, Urban Water Journal, DOI: 10.1080/1573062X.2014.939092.

OECD (2007). Infrastructure to 2030 - Vol. 2. Mapping Policy for Electricity, Water and Transport. Paris: OECD publishing. 